\title{
Inverse modeling of the biodegradation of emerging organic contaminants in the soil- plant system
}

Hurtado, Carlos; Trapp, Stefan; Bayona, Josep M.

Published in:

Chemosphere

Link to article, DOI:

10.1016/j.chemosphere.2016.04.134

Publication date:

2016

Document Version

Peer reviewed version

Link back to DTU Orbit

Citation (APA):

Hurtado, C., Trapp, S., \& Bayona, J. M. (2016). Inverse modeling of the biodegradation of emerging organic contaminants in the soil-plant system. Chemosphere, 156, 236-244.

https://doi.org/10.1016/j.chemosphere.2016.04.134

\section{General rights}

Copyright and moral rights for the publications made accessible in the public portal are retained by the authors and/or other copyright owners and it is a condition of accessing publications that users recognise and abide by the legal requirements associated with these rights.

- Users may download and print one copy of any publication from the public portal for the purpose of private study or research.

- You may not further distribute the material or use it for any profit-making activity or commercial gain

- You may freely distribute the URL identifying the publication in the public portal 


\section{Inverse modeling of the biodegradation of}

\section{3 emerging organic contaminants in the soil-plant}

4 system

6 Carlos Hurtado ${ }^{a}$, Stefan Trapp ${ }^{\mathrm{b}},{ }^{*}$, Josep M. Bayona ${ }^{\mathrm{a}}$

7 a Environmental Chemistry Department, IDAEA-CSIC, Jordi Girona 18-26, E808034 Barcelona, Spain

$9{ }^{b}$ Technical University of Denmark, DK-2800 Kongens Lyngby, Miljøvej bd 113,

10 Denmark 


\section{Abstract}

15 Understanding the processes involved in the uptake and accumulation of organic

16 contaminants into plants is very important to assess the possible human risk

17 associated with. Biodegradation of emerging contaminants in plants has been

18 observed, but kinetical studies are rare. In this study, we analyse experimental

19 data on the uptake of emerging organic contaminants into lettuce derived in a

20 greenhouse experiment. Measured soil, root and leaf concentrations from four

21 contaminants were selected within the applicability domain of a steady-state two-

22 compartment standard plant uptake model: bisphenol A (BPA), carbamazepine

23 (CBZ), triclosan (TCS) and caffeine (CAF). The model overestimated

24 concentrations in most cases, when no degradation rates in plants were entered.

25 Subsequently, biodegradation rates were fitted so that the measured

26 concentrations were met.

27 Obtained degradation kinetics are in the order, $\mathrm{BPA}<\mathrm{CAF} \approx \mathrm{TCS}<\mathrm{CBZ}$ in roots,

28 and $\mathrm{BPA} \approx \mathrm{TCS}<\mathrm{CBZ}<<\mathrm{CAF}$ in leaves. Kinetics determined by inverse modeling

29 are, despite the inherent uncertainty, indicative of the dissipation rates. The

30 advantage of the procedure that is additional knowledge can be gained from

31 existing experimental data. Dissipation kinetics found via inverse modeling is not a

32 conclusive proof for biodegradation and confirmation by experimental studies is

33 needed.

34 Keywords: dissipation; kinetics; plants; model; emerging organic contaminants. 


\section{Introduction}

37 Pharmaceuticals, biocides and drugs as well as other chemicals from human use

38 reach sewer systems and are partially removed during conventional wastewater

39 treatment processes (Halling-Sørensen et al., 1998). By irrigation with reclaimed

40 water, or sewage sludge amendment, these chemical residues may reach

41 agricultural soils. Uptake into crops can lead to human exposure to such chemicals

42 (Hospido et al., 2010). In the European Union, the environmental risk from

43 pharmaceutical products is assessed only for veterinary drugs (EMA, 2011), and

44 only few pharmaceuticals and drugs are regularly monitored according with the

45 Watch List of the Water Framework Directive (Directive 2008/105/EC). Then,

46 human exposure to emerging organic contaminants (EOCs) relies partly on

47 scientific studies, and an increasing number of studies on their uptake into

48 vegetables is reported (Wu et al., 2015; Miller et al., 2016).

49 Prosser and Sibley (2015) found no human health hazards from the plant uptake of

50 the "majority of pharmaceuticals and personal care products". However, Malchi et

51 al. (2015) stated that "current data are insufficient to support a comprehensive

52 human health risk assessment" of pharmaceuticals and personal care products in

53 plant tissue due to biosolids and manure amendments, or reclaimed water

54 irrigation. Due to the high number of compounds potentially present in reclaimed

55 water (Calderón-Preciado et al., 2011; Loos et al., 2013; Luo et al., 2014),

56 prediction tools for pre-screening of chemicals and priority setting for safety

57 assessments are of high value (Polesel et al., 2015). Prosser et al. (2014)

58 examined the ability of two prediction models to estimate the uptake of 
59 pharmaceuticals and personal care products (PPCPs) into plants from sludge-

60 amended soils. Predictions of plant uptake of PPCPs within one order of

61 magnitude near the experimental results were achieved for some of the

62 investigated compounds. Polesel et al. (2015) developed and tested a simulation

63 tool for fate prediction from human pharmaceuticals down the drain through a

64 sewage treatment plant and via sludge amendment and irrigation to agricultural

65 fields and crops. However, simulations were performed disregarding degradation in

66 plants. To reduce discrepancies between model predictions and measurements,

67 the authors stressed the need for more measured input parameters (e.g., $K_{d}$ ) and

68 kinetics of biotransformation in plant tissues.

69 For polar compounds, efficient translocation in xylem of plants can be expected

70 (Trapp, 2007; Dettenmaier et al., 2009), leading to accumulation in leaves, if no

71 losses occur. Biodegradation has been identified as among the most relevant

72 dissipation processes of chemicals from plants (Fantke et al., 2012; Jacobsen et

73 al., 2015), but is often unknown or uncertain and depends on a number of factors,

74 such as species and temperature (Fantke and Juraske, 2013; Fantke et al., 2014;

75 Jacobsen et al., 2015). Methods to measure metabolism in soil and plants have

76 been developed early, typically employing the use of ${ }^{14} \mathrm{C}$-labeled compounds to

77 close the mass balance (Trapp et al., 1990; Kästner et al., 2014). There are also

78 OECD guidelines for pesticide metabolism in crops to elucidate the degradation

79 pathway available (i.e. OECD Tests Nr. 501, 502). The drawback is that studies

80 with hot labels are expensive, and safety issues arise. These safety issues can be 
81 solved by using stable isotopes $\left({ }^{13} \mathrm{C}\right.$ and $\left.{ }^{15} \mathrm{~N}\right)$, but require IRM-MS equipment, if

82 isotopically labeled compounds are available at all.

83 An alternative method to assess biodegradation that has rarely been attempted is

84 the use of inverse modeling. Hereby, predictable loss due to physical-chemical

85 processes (volatilization, translocation, dilution) is contrasted with measured

86 dissipation. The difference is contributed to biodegradation. This method cannot

87 prove degradation but can help to quantify loss processes (Jacobsen et al., 2015).

88 The kinetics of biodegradation affects the relation between concentrations in plants

89 and soil. First-order degradation kinetics, either in soil or in plants, will change the

90 slope of the trend line (lower for degradation in plants, higher for degradation in

91 soil), but the relation will remain linear. In a study with lettuce grown under

92 controlled conditions and irrigated with water containing eight emerging organic

93 contaminants (EOCs), Hurtado et al. (2016) obtained mostly linear correlations

94 between watering concentrations and concentrations measured in roots and

95 leaves. Besides hydrophobicity (log $D_{O w}$ ) of chemicals, their persistence was

96 identified as a key determinant for plant uptake and accumulation of the EOCs.

97 In this study, we supplemented a standard plant uptake model (Rein et al., 2011)

98 with different degradation kinetics for soil and plant. The model was parameterized

99 to simulate the uptake experiments of emerging organic contaminants into lettuce

100 performed by Hurtado et al. (2016). Degradation rate constants in soil were derived

101 from the measured concentrations, while rates in leaves and roots were fitted, 
102 based on the difference between the model prediction (without degradation) and

103 the measured data. The resulting rates were compared to data from literature.

\section{Materials and methods}

\subsection{Experimental section}

107 Experiments were conducted in a glass greenhouse located in Viladecans

108 (Barcelona, Spain) as described in Hurtado et al. (2016). Briefly, lettuce (Lactuca

109 sativa) was planted in pots in a mixture of perlite and sand (2:1 v/v, approx. $1.2 \mathrm{~kg})$

110 and watered with Hoagland nutrient solution (Hoagland and Arnon, 1950) diluted

111 1:1 with rain water. $A$ dose of $50 \mathrm{~mL}$ of irrigation water was applied to each

112 experimental unit per day. The number of daily irrigations was regulated to keep

113 water in the soil below field capacity, thereby preventing leachate production.

114 After 40 days, EOCs were added to soil. Five treatments consisted of direct

115 application of $0,14,35,70$ and $140 \mu \mathrm{g}$ of eight EOCs per experimental unit in eight

116 applications during 28 days. Taking into account the soil substrate mass in each

117 experimental unit, this corresponds to an average nominal initial concentration in

118 the substrate of $0,11.7,29.2,58.3$ and $116.7 \mu \mathrm{g} \mathrm{kg}^{-1} \mathrm{dw}$. After 28 days, substrate,

119 roots and leaves of lettuces were separated and analyzed. The data used in this

120 study can be found in the SI and are also reported in Hurtado et al. (2016).

121 The EOCs measured in the experimental study were bisphenol $A$, caffeine, 122 carbamazepine, ibuprofen, propranolol, sulfamethazine, triclosan and tonalide. All 123 chemicals were purchased from Sigma-Aldrich (St. Louis, MO, USA), except 
124 tonalide from Ventós (Sant Just Desvern, Spain). The extraction of EOCs from

125 vegetal tissue and substrate and the analytical parameters are listed in Hurtado et 126 al. (2016). The properties of the compounds are listed in Table 1.

127 Table 1. Properties of the compounds added in the experiment by Hurtado et al. 128 (2016). All values were obtained using ACD Advanced Chemistry Development 129 (2010), ACD/i-lab 2.0. Toronto, 2010.

\begin{tabular}{|c|c|c|c|c|c|c|c|}
\hline EOC & $\begin{array}{r}\text { Molar } \\
\text { mass } \\
\left(\mathrm{g} \mathrm{mol}^{-1}\right)\end{array}$ & $\begin{array}{r}\mathrm{pKa} \\
\text { values }\end{array}$ & $\begin{array}{r}\begin{array}{r}\text { Speciation } \\
(z)\end{array}\end{array}$ & $\begin{array}{l}\text { Neutral } \\
\log K_{\mathrm{ow}}\end{array}$ & $\begin{array}{r}\log D_{\text {ow }} \\
\text { at pH } 6.4\end{array}$ & $\begin{array}{l}\log \\
K_{\text {AW }}\end{array}$ & $\begin{array}{r}\log \\
K_{\text {HSA }}\end{array}$ \\
\hline $\begin{array}{l}\text { Bisphenol A } \\
\text { (BPA) }\end{array}$ & 228.29 & $\begin{array}{l}9.7 \\
10.5\end{array}$ & $0 /-1 /-2$ & 3.46 & 3.46 & -9.43 & 3.57 \\
\hline Caffeine (CAF) & 194.19 & NA & 0 & 0.11 & 0.11 & -8.83 & 2.53 \\
\hline $\begin{array}{l}\text { Carbamazepine } \\
\text { (CBZ) }\end{array}$ & 236.27 & NA & 0 & 23 & 2.23 & -7.20 & 3.74 \\
\hline Ibuprofen (IBU) & 206.28 & 4.3 & $0 /-1$ & 3.63 & 1.53 & -5.21 & 4.42 \\
\hline $\begin{array}{l}\text { Propranolol } \\
\text { (PROP) }\end{array}$ & 259.34 & 9.5 & $1 / 0$ & 2.69 & 0.13 & -10.49 & 3.54 \\
\hline $\begin{array}{l}\text { Sulfamethazine } \\
\text { (SMT) }\end{array}$ & 278.33 & $\begin{array}{l}3.1, \\
7.2\end{array}$ & $1 / 0 /-1$ & 0.31 & 0.25 & -11.33 & 4.1 \\
\hline Tonalide (TON) & 258.40 & NA & 0 & 5.71 & 5.71 & -2.04 & 4.71 \\
\hline Triclosan (TCS) & 289.54 & 8.8 & $0 /-1$ & 5.21 & 5.21 & -4.08 & 4.81 \\
\hline
\end{tabular}

130 NA: Not applicable; $z$ is charge number (valence); $K_{\mathrm{ow}}\left(\mathrm{L} \mathrm{L}^{-1}\right)$ is the partition 131 coefficient octanol to water for the neutral molecule; $D_{\mathrm{ow}}\left(\mathrm{L} \mathrm{L}^{-1}\right)$ is the apparent 132 partition coefficient of the neutral and ionic molecules at pH 6.4 (soil pH); $K_{\mathrm{AW}}\left(\mathrm{L} \mathrm{L} \mathrm{L}^{-1}\right)$ 133 is the partition coefficient air to water for neutral molecules (known as 134 dimensionless Henry's Law constant) and $K_{\mathrm{HSA}}\left(\mathrm{L} \mathrm{mol}^{-1}\right)$ is the adsorption to human 135 serum albumin (as predictor for the adsorption to proteins).

\subsection{Model section}

138 The plant uptake model is based on the commonly used "standard model" for plant 139 uptake (Legind and Trapp, 2009; Legind et al., 2011; Rein et al., 2011; Trapp, 
140 2015). Modifications were introduced to consider different degradation kinetics.

141 This version of the model is primarily designed for neutral compounds. As long as

142 the fraction of ionic molecules is small, ionization only slightly affects the outcome

143 when measured $K_{d}$-values are used. PROP, IBU and SMT were not included in the

144 plant uptake simulations because the ionization prohibits the use of this model

145 version. TON was excluded because of its high volatility. In a separate approach,

146 Michaelis-Menten degradation kinetics in roots and leaves was calculated, but for

147 mathematical reasons with initial (constant) concentration in soil.

148 The underlying differential equation for the change of concentration in roots $\left(C_{R}\right.$,

$149 \mathrm{mg} \mathrm{kg}^{-1}$ ) with time $t(\mathrm{~d})$ is

150 + inflow from soil - translocation upwards - dilution by growth - degradation

$151 \frac{d C_{R}}{d t}=\frac{Q}{M_{R}} \times \frac{C_{S}}{K_{d}}-\frac{Q}{M_{R} \times K_{R W}} \times C_{R}-k_{\text {growth }} \times C_{R}-$ degradation

152 where $R$ is index for roots, $Q$ is the transpiration $\left(\mathrm{L} \mathrm{d}^{-1}\right), M$ is the plant mass $(\mathrm{kg})$,

$153 C_{S}$ is the concentration of chemical in soil $\left(\mathrm{mg} \mathrm{kg}^{-1}\right), K_{\mathrm{d}}$ is the distribution coefficient

154 between substrate and pore water $\left(\mathrm{L} \mathrm{kg}^{-1}\right), K_{\mathrm{RW}}$ is partition coefficient roots to

155 water (and xylem sap) $\left(\mathrm{L} \mathrm{kg}^{-1}\right)$, and $k_{\text {growth, }}$ is the growth rate of roots $\left(\mathrm{d}^{-1}\right)$.

156 The differential equation for the change of concentration in leaves $\left(C_{L}, \mathrm{mg} \mathrm{kg}^{-1}\right)$

157 with time, neglecting uptake of chemical from air, is

158 + translocation from roots - loss to air - dilution by growth - degradation 
$159 \frac{d C_{L}}{d t}=\frac{Q}{M_{L} \times K_{R W}} \times C_{R}-\frac{A_{L} \times g \times 1000 \mathrm{Lm}^{-3}}{K_{L A} \times M_{L}} \times C_{L}-k_{\text {growth } L} \times C_{L}-$ degradation (2)

160 where $L$ is index for leaves, $A$ is area $\left(\mathrm{m}^{2}\right), \mathrm{g}$ is conductance $\left(\mathrm{m} \mathrm{d}^{-1}\right)$ and $K_{\mathrm{LA}}$ is 161 partition coefficient between leaves and air $\left(\mathrm{L} \mathrm{kg}^{-1}\right)$.

163 a) Coupled dynamic differential equation system with first-order degradation

164 The concentrations in soil, roots and shoots are calculated from a system of 165 coupled ordinary differential equations that form a triangular matrix and are solved 166 analytically.

167 The concentration in soil is considered time-dependent, with

$168 C_{S}(t)=C_{S}(0) \times e^{-k_{1} t}$

169 The loss rate from soil $k_{1}$ (matrix element 1 ) was calculated from the measured 170 initial and final concentrations at time $t, C_{\mathrm{S}}(t)$, assuming first-order loss due to

171 degradation, plant uptake and volatilization:

172

$k_{1}=\frac{\ln C_{S}(0) / C_{S}(t)}{t}$

173 The transfer rate from soil to roots is

$174 \quad k_{12}=\frac{Q}{M_{R} K_{d}}$ 
175 The rate $k_{2}$ is the sum of all loss terms (to shoots, dilution, degradation) from roots $176 \quad\left(d^{-1}\right)$

$$
k_{2}=\frac{Q}{M_{R} \times K_{R W}}+k_{\text {growth } R}+k_{R}
$$

$178 k_{R}$ is the 1 st order degradation rate that is to be fitted.

179 The rate $k_{3}\left(d^{-1}\right)$ is the sum of all loss terms (to air, dilution, degradation) from 180 leaves

$$
k_{3}=\frac{A_{L} \times g \times 1000 L^{-3}}{K_{L A} \times M_{L}}+k_{\text {growth } L}+k_{L}
$$

$182 k_{\mathrm{L}}$ is the $1^{\text {st }}$ order degradation rate that is to be fitted.

183 The transfer rate from roots to leaves is

$$
k_{23}=\frac{Q}{M_{L} K_{R W}}
$$

185 The analytical solution for the concentration in roots (matrix element 2) is

$$
C_{R}(t)=\frac{k_{12} \times C_{S}(0)}{k_{2}-k_{1}} \times\left(e^{-k_{1} \times t}-e^{-k_{2} \times t}\right)
$$

187 and for leaves (matrix element 3 ) is

$$
C_{L}(t)=k_{12} k_{23} C_{S}(0)\left\{\frac{e^{-k_{1} t}}{\left(k_{2}-k_{1}\right)\left(k_{3}-k_{1}\right)}+\frac{e^{-k_{2} t}}{\left(k_{1}-k_{2}\right)\left(k_{3}-k_{2}\right)}+\frac{e^{-k_{3} t}}{\left(k_{1}-k_{3}\right)\left(k_{2}-k_{3}\right)}\right\}
$$


189 This model resembles the cascade model presented and tested by Rein et al.

190 (2011) and applied by Legind et al. (2011) and Prosser et al. (2014).

192 b) Michaelis-Menten degradation kinetics in roots and leaves

193 Enzymatic reactions often follow the Michaelis-Menten kinetics

194 degradation $=\frac{v_{\max } \times C}{K_{M}+C}$

195 where $v_{\max }$ is the maximal enzymatic removal in roots or leaves $\left(\mathrm{mg} \mathrm{kg}^{-1} \mathrm{~d}^{-1}\right)$ and

$196 K_{\mathrm{M}}\left(\mathrm{mg} \mathrm{kg}^{-1}\right)$ is the concentration at which removal is half $v_{\max }$. With Michaelis-

197 Menten type kinetics, the shape of the trendline between concentrations in soil and

198 plant is no longer linear. This kinetics has been observed for the degradation of

199 cyanide by plants (Larsen et al., 2004; Yu et al., 2004) and for the exclusion of salt

$200 \mathrm{NaCl}$ and $\mathrm{NaF}$ from roots (Trapp et al., 2008; Clausen et al., 2015). The

201 assumption of steady-state was made to allow for a closed analytical solution, and

202 requires constant concentration in soil $C_{S}(0)$. The steady-state leads to a quadratic

203 equation which was solved using Vieta's formulas (Larsen et al., 2004; Trapp et al., 204 2008).

205 The comparison of experimental values from different studies with different 206 concentration levels is done by calculation of root concentration factor (RCF) and 207 leaf concentration factor (LCF) which are defined as

$208 R C F=\frac{C_{R}\left(t_{2}\right)}{C_{S}\left(t_{1}\right)}$ 
$209 L C F=\frac{C_{L}\left(t_{2}\right)}{C_{S}\left(t_{1}\right)}$

210 Here, $t_{1}$ and $t_{2}$ stand for the time when the concentrations were measured. While $t_{2}$

211 (the time when the concentration in root and leaf is determined) typically refers to

212 the time of harvest, there is no standard for $t_{1}$, and initial, nominal or final (at

213 harvest) concentrations have been used for the calculation of RCF and LCF.

\section{Model input data}

215 Where available, input data for the plant properties were taken from the

216 experiment. As shown recently, plant properties can significantly affect the

217 outcome of the model simulations (Trapp, 2015). The experiment was carried out

218 in a greenhouse in Spain, but in the winter period. Growth was moderate (growth

219 rate $0.05 \mathrm{~d}^{-1}$ ), and the ratio of transpiration to plant mass was relatively low (Table 220 2).

221 Table 2. Input data for the simulation of the uptake experiment with lettuce. Data

222 shown are for an individual pot. Displayed is the data set for an experiment with

223 carbamazepine (experiment number 17). Data source Hurtado et al. (2016)

\begin{tabular}{|l|l|l|l|l|}
\hline & Symbol & value & unit & Comment \\
\hline distribution coefficient & $K_{\mathrm{d}}$ & 0.72 & $\mathrm{~L} \mathrm{~kg}^{-1}$ & measured \\
\hline total loss rate & $k_{1}$ & 0.0895 & $\mathrm{~d}^{-1}$ & $\begin{array}{l}\text { calculated from } \\
\text { measurements }\end{array}$ \\
\hline water content roots & $W_{R}$ & 0.898 & $\mathrm{~L} \mathrm{~kg}^{-1}$ & measured \\
\hline lipid content roots & $L_{R}$ & 0.025 & $\mathrm{~kg} \mathrm{~kg}^{-1}$ & default \\
\hline
\end{tabular}




\begin{tabular}{|l|l|l|l|l|}
\hline mass of roots & $M_{R}$ & 0.0833 & $\mathrm{~kg}$ & measured \\
\hline transpiration & $Q$ & 0.053 & $\mathrm{~L} \mathrm{~d}^{-1}$ & $\begin{array}{l}\text { calculated from } \\
\text { added water }\end{array}$ \\
\hline growth rate root & $k_{\text {growth }, \mathrm{R}}$ & 0.05 & $\mathrm{~d}^{-1}$ & $\begin{array}{l}\text { calculated from } \\
\text { measurements }\end{array}$ \\
\hline shoot mass & $M_{L}$ & 0.2227 & $\mathrm{~kg}$ & measured \\
\hline leaf area & $A$ & 1 & $\mathrm{~m}^{2}$ & default \\
\hline conductance & $g$ & 0.001 & $\mathrm{~m} \mathrm{~s}^{-1}$ & default \\
\hline lipid content leaves & $L_{L}$ & 0.02 & $\mathrm{~g} \mathrm{~g}^{-1}$ & default \\
\hline water content leaves & $W_{L}$ & 0.954 & $\mathrm{~g} \mathrm{~g}^{-1}$ & measured \\
\hline $\begin{array}{l}\text { time between dosing } \\
\text { and harvest }\end{array}$ & $t$ & 28 & $\mathrm{~d}$ & measured \\
\hline growth rate shoots & $k_{\text {growth }, \mathrm{L}}$ & 0.05 & $\mathrm{~d}^{-1}$ & $\begin{array}{l}\text { calculated from } \\
\text { measurements }\end{array}$ \\
\hline
\end{tabular}

224

225

226

227

228

229

230

231 Root concentration factor (RCF, $\mathrm{kg} \mathrm{kg}^{-1} \mathrm{dw}$ ) and leaf concentration factor (LCF, $\mathrm{kg}$

$232 \mathrm{~kg}^{-1} \mathrm{dw}$ ) were calculated as the slopes of the linear regression of the concentration

233 in plant versus either the initial (nominal) or the final concentration in the soil

234 substrate. Figure 1 shows the RCFs and LCFs of CBZ and IBU. RCFs obtained for 
235 CBZ were rather similar when initial or final concentrations of CBZ in soil were 236 used to establish the regression. The slope, interpreted as RCF, was $10.4 \mathrm{~kg} \mathrm{~kg}^{-1}$ $237 \mathrm{dw}$ with the initial and $9.6 \mathrm{~kg} \mathrm{~kg}^{-1} \mathrm{dw}$ with the final substrate concentration, 238 however, the $y$-intercept went from $-45 \mu \mathrm{g} \mathrm{kg}^{-1} \mathrm{dw}$ to $+92 \mu \mathrm{gg}^{-1} \mathrm{dw}$. Also the LCF 239 of CBZ changed very little, from 17.6 to $15.1 \mathrm{~kg} \mathrm{~kg}^{-1} \mathrm{dw}$ (but with high Y-intercept 240 of $268 \mu \mathrm{g} \mathrm{kg}^{-1} \mathrm{dw}$ ). Conversely, for IBU the slope of the RCF regression changed 241 from 2.0 to $9.4 \mathrm{~kg} \mathrm{~kg}^{-1} \mathrm{dw}$ and from 0.20 to $0.94 \mathrm{~kg} \mathrm{~kg}^{-1} \mathrm{dw}$ for the LCF with initial 242 or final soil concentrations, and $\mathrm{Y}$-intercepts were negative. The slopes for the 243 other compounds can be seen in Figure S1 (RCF) and S2 (LCF). All compounds 244 showed good uptake into roots with $\mathrm{RCF}>1 \mathrm{~kg} \mathrm{~kg}^{-1} \mathrm{dw}$. Translocation to leaves 245 was highest for CBZ and lowest for TCS. Most slopes increased when the final 246 substrate concentration was used for the regression. 

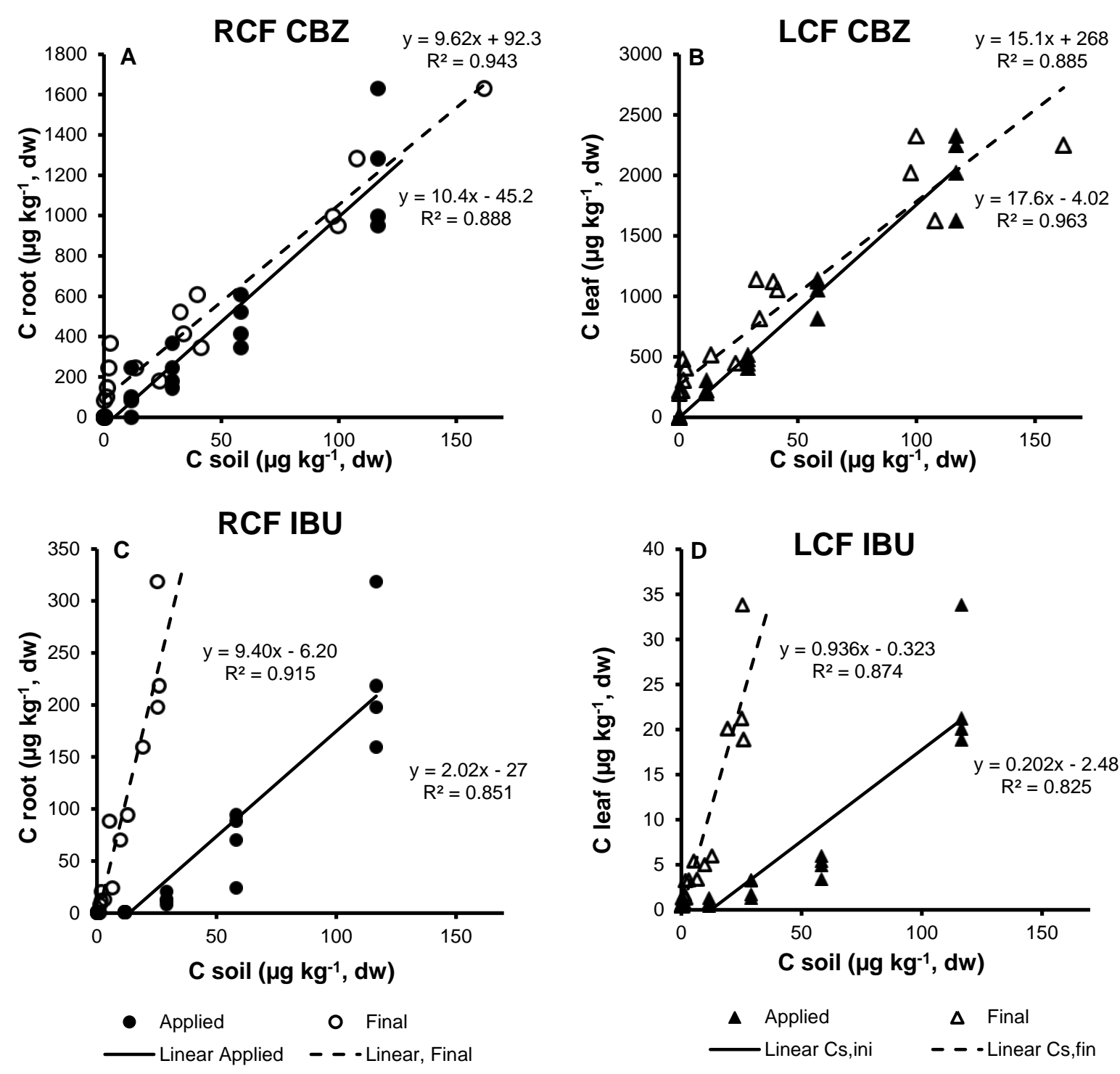

249 Figure 1. Root and leaf bioconcentration factors (RCFs and LCFs) of 250 carbamazepine (CBZ) and ibuprofen (IBU). The solid and dashed lines represent 251 the linear regression of the root and leaf concentration on the applied initial and the 252 final soil concentration.

253 Modeling

254 The data obtained in the experiments (Table 2), such as dry weights at harvest and 255 transpiration, were used to simulate plant uptake with the standard plant uptake 256 model with degradation as described above (Eqs. 1-9). The loss rates from soil $\left(k_{1}\right)$ 
257 were calculated from the nominal initial concentration and the final measured 258 concentration assuming exponential ( $1^{\text {st }}$ order) decay (Table 3 ). Except one case 259 (CAF, lowest applied amount), the loss rate from soil of all studied EOCs 260 decreased when the initial concentration increased. For example, for CBZ the loss 261 rates from soil were $0.090,0.037,0.015$ and $0.006 \mathrm{~d}^{-1}$ for the four treatments $(11.7$, $26229.2,58.3$ and $116.7 \mu \mathrm{gg}^{-1} \mathrm{dw}$ ). For IBU, the rates were $0.100,0.094,0.067$ and $2630.055 \mathrm{~d}^{-1}$ for the same treatments.

264 Degradation rates in roots and leaves were determined by fitting simulated 265 concentrations in plants to the measured ones. Figure 2 shows an example for the 266 simulations with fit. The simulation of BPA succeeds without added degradation in 267 roots or leaves, but only when dissipation from soil is considered. For CAF, on the 268 other hand, the simulation improves when a fast degradation rate in leaves is 269 assumed. The results of the linear model appear curved due to the changing 270 degradation rates in soil. Judged from the correlation between calculated and 271 average measured concentrations, the Michaelis-Menten kinetics in this case is 272 closer to the measured result. In all cases, however, omitting degradation in soil 273 (labeled as 00 in Fig. 2) leads to drastic overestimation. Fitted 1st-order dissipation 274 rates of selected EOCs are shown in Table 3b. The fastest first-order dissipation 275 rate from roots was fitted for CBZ $\left(0.35 \mathrm{~d}^{-1}\right)$. Dissipation from roots also affects 276 leaves, but nonetheless a rapid dissipation rate of CAF from leaves was required to 277 meet the measured data. The adjusted parameters for the Michaelis-Menten 278 kinetics in roots and leaves can be found in Table 3c. Fitted $v_{\max }$ was higher in 279 roots than in leaves, except for CAF. The values have to be taken with care 
280 because the two parameters cannot be verified independently, but also because

281 the fitted degradation must replace partly the missing dissipation from soil which,

282 for mathematical reasons, could not be considered in the simulation with Michaelis-

283 Menten kinetics.
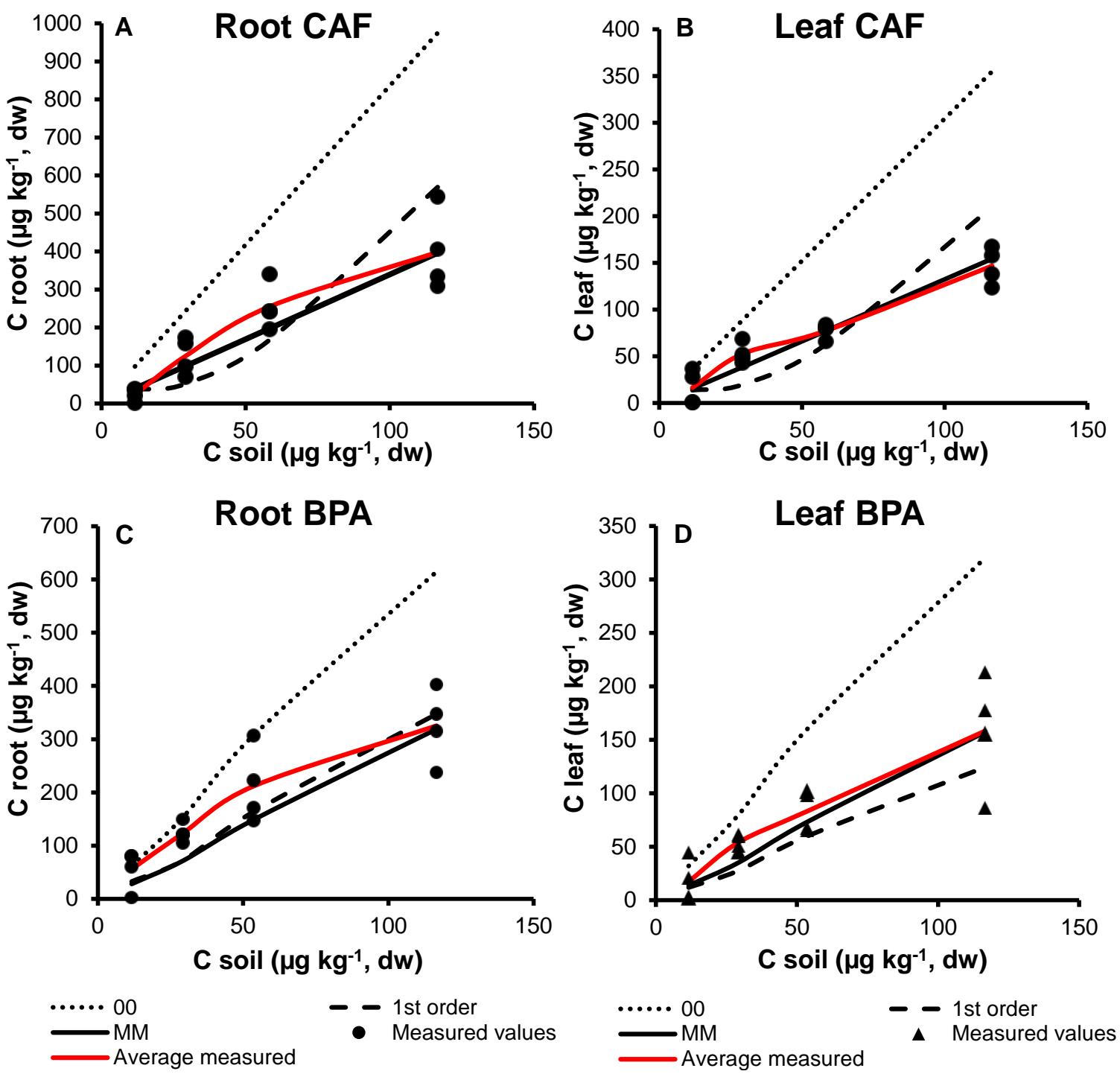

285 Figure 2. Simulated and measured concentrations in a) top left: CAF roots, b) top

286 right: CAF leaves, c) bottom left: BPA roots; d) bottom right: BPA leaves. Solid

287 points represent measured values; 00: no degradation in soil or plant; 1 st: 1 st order 
288 degradation in soil, roots and leaves; MM: Michaelis-Menten degradation in roots 289 and leaves.

290 Table 3a. Calculated first order degradation rates in soil, $k_{\text {soil, }}\left(d^{-1}\right)$ for the four

291 different treatments of selected EOCs (in brackets: standard deviation, $n=4$ ).

\begin{tabular}{|c|c|c|c|c|c|c|}
\hline $\begin{array}{c}\text { Treatment } \\
\left(\boldsymbol{\mu} \mathbf{~ k g}^{-1} \mathbf{d w}\right)\end{array}$ & BPA & CAF & CBZ & IBU & PROP & TCS \\
\hline $\mathbf{1 1 . 7}$ & $0.039(0.030)$ & $0.038(0.008)$ & $0.109(0.040)$ & $0.104(0.010)$ & $0.088(0.024)$ & $0.008(0.010)$ \\
\hline $\mathbf{2 9 . 2}$ & $0.038(0.008)$ & $0.060(0.004)$ & $0.058(0.048)$ & $0.099(0.013)$ & $0.080(0.023)$ & $0.001(0.012)$ \\
\hline $\mathbf{5 8 . 3}$ & $0.031(0.005)$ & $0.044(0.012)$ & $0.017(0.004)$ & $0.073(0.015)$ & $0.076(0.034)$ & $0.001(0.020)$ \\
\hline $\mathbf{1 1 6 . 7}$ & $0.029(0.011)$ & $0.022(0.006)$ & $0.001(0.009)$ & $0.059(0.005)$ & $0.063(0.032)$ & $0.001(0.008)$ \\
\hline
\end{tabular}

292

293 Table 3b. Fitted first-order degradation rates in roots and leaves of selected EOCs.

294

\begin{tabular}{|c|l|l|l|l|}
\hline & BPA & CAF & CBZ & TCS \\
\hline $\boldsymbol{k}_{\text {root }}\left(\mathbf{d}^{-1}\right)$ & 0.00 & 0.05 & 0.35 & 0.10 \\
\hline $\boldsymbol{k}_{\text {leat }}\left(\mathbf{d}^{-1}\right)$ & 0.00 & 1.50 & 0.05 & 0.00 \\
\hline
\end{tabular}

295 Table 3c. Adjusted Michaelis-Menten parameters $v_{\max }\left(\mathrm{mg} \mathrm{kg}^{-1} \mathrm{~d}^{-1}\right)$ and $K_{\mathrm{M}}\left(\mathrm{mg} \mathrm{kg}^{-}\right.$

$296{ }^{1}$ ) for enzymatic degradation in kinetics equation of selected EOCs.

297

\begin{tabular}{|l|c|c|c|c|}
\hline & BPA & CAF & CBZ & TCS \\
\hline $\boldsymbol{V}_{\max }$ root & 0.01 & 6.0 & 0.20 & 0.20 \\
\hline $\boldsymbol{K}_{\mathrm{M}}$ root & 0.10 & 5.0 & 0.45 & 1.00 \\
\hline $\boldsymbol{V}_{\max }$ leaf & 0.0003 & 7.0 & 0.07 & 0.00 \\
\hline $\boldsymbol{K}_{\mathrm{M}}$ leaf & 0.1 & 5.0 & 0.0001 & none \\
\hline
\end{tabular}

298 4. DISCUSSION 
300 Bioconcentration factors $(\mathrm{BCF})$ are defined as concentration ratio between 301 organism and surrounding medium. However, the calculations can be done in 302 various ways. Some authors calculate BCFs from the concentration in the irrigation 303 water, others from the concentration in soil and some from the concentration in the 304 soil solution. Moreover, in some studies the nominal concentration is used while 305 others use the final concentration in soil at harvest to calculate the BCFs. In this 306 study, BCFs were derived as slope of the regression line so measurements at all 307 concentrations contributed simultaneously, without contribution of background $(\mathrm{Y}-$ 308 intercept), and with both initial (nominal) and final concentration (Figures SI1, SI2).

309 For CBZ there were no big differences in the BCF when it was calculated with 310 initial or final substrate concentration (Figure 1). On the other hand, for IBU the

311 difference was almost 5 times (2.0 to $9.4 \mathrm{~g} \mathrm{~g}^{-1} \mathrm{dw}$ ). Thus, it is important to consider 312 that dissipation from soil or substrate will affect the BCF.

313 For most of the studied EOCs, experimental BCFs can be found in the literature

314 (Table 4). The reported values show large variance and are generally far higher in 315 hydroponics. In comparison to BCFs derived from experiments with soil, our values 316 are at the higher end, probably due to the lower adsorption capacity of perlite and 317 sand, compared to soil organic matter.

318 The half-lives (DT50) in the perlite and sand mixture are slower than those derived 319 in soil. The perlite and sand mixture was chosen as a substrate because in 320 laboratory studies we observed that there were lower interactions than when using 
321 soil. The uptake simulations were done with measured $K_{\mathrm{d}}$-values, thus, the 322 difference in adsorption does not affect the simulations. But the substrate for this 323 experiment lacked of organic matter, which can be used as main substrate by 324 bacteria degrading co-metabolically EOC. This may explain why most loss rates 325 from our substrate were lower than rates found in soil (Fent et al., 2003; Langdon 326 et al., 2012; Matsumura et al., 2015). For example, DT50 of bisphenol A in soil 327 have been determined from 0.5 to 7 days (Cousins et al., 2002, Ying et al., 2005 328 and $\mathrm{Xu}$ et al., 2009), while we found half-lives from 17.8 to 23.9 days. BPA 329 dissipation is related to bacteria in soil and it dissipates faster in more aerobic 330 environments (Fent et al., 2003). 
331 Table 4. Experimental values of bioconcentration factors and dissipation times in soils reported and in this study.

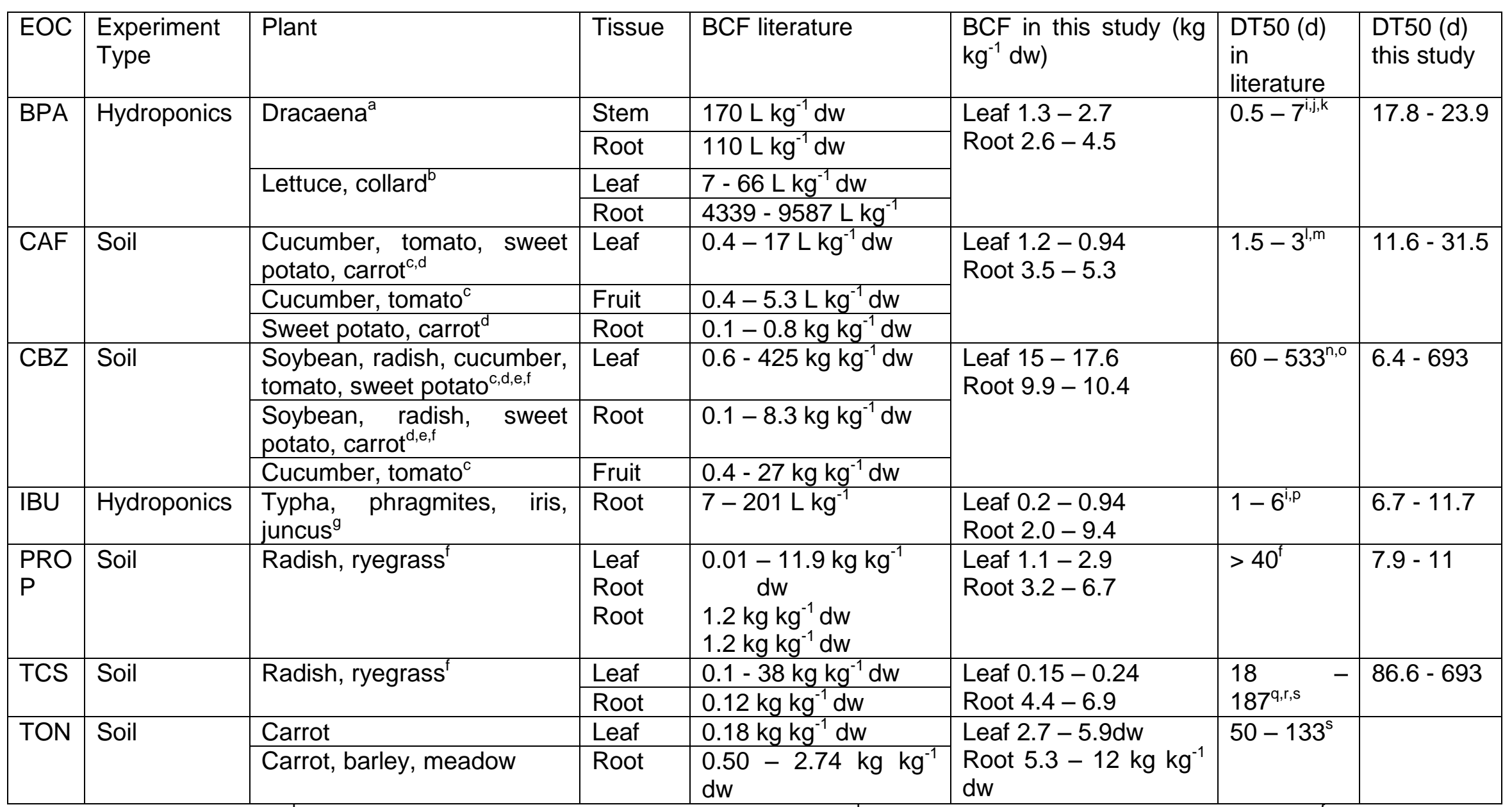


338 Dissipation rates from soil in Table $3 a$ were calculated from initial nominal and final 339 measured substance concentrations in the substrate. Rates decreased with 340 increasing concentrations. Such kinetics, i.e. decreasing (pseudo) first-order rates

341 with increasing substrate concentrations, can occur by enzymatic degradation 342 when the half-saturation concentration $K_{M}$ of the reaction is within the range of

343 occurring concentrations and when at the same time the amount of enzymes is 344 constant. Thus, co-metabolic (non-growth) degradation by microbes living in the 345 substrate or near and in the roots, but also degradation by roots itself can lead to 346 this kinetics. At higher soil concentrations, PROP, IBU, BPA and CAF had the 347 highest dissipation rates, while CBZ and TCS showed the lowest dissipation. As it 348 can be seen in Table 4, several studies suggest that CBZ is relative persistent with 349 half-lives in soil (DT50) over 60 days. Moreover, TCS and its metabolites were 350 found in soil still four years after the application with biosolids (Macherius et al., 351 2014). The other compounds are more labile to degradation. For example, 352 metabolites of BPA have been found in soil such as 4-hydroxyacetophenone, 4353 hydroxybenzaldehyde and 4-hydroxybenzoic acid (Dodgen et al., 2014). Hurtado et 354 al. (2016) determined the concentrations of test chemicals both in the bulk soil, and 355 in the vicinity of roots. Only TCS showed an enrichment in the soil around roots, 356 underlining its persistence. Low concentrations in the soil near roots were found for

357 PROP and IBU, which also had the highest loss rates from soil (Table 3a). This 
358 makes it likely that degradation is enhanced by roots. Furthermore, enantiomeric

359 fractionation of IBU was observed, with an enrichment of the $S$-enantiomer.

360 Inverse modeling

361 Inverse modeling can be a powerful tool to determine missing processes or rate

362 constants and is often used for model calibration. Jacobsen et al. (2015) used the

363 technique to find missing in-planta-degradation of pesticides, and the principle

364 applied here is similar: model predictions are compared to measured

365 concentrations, and the difference is contributed to dissipation by degradation. This

366 method is of course highly uncertain because both model simulation and

367 experiment have their own uncertainties, and unknown dissipation processes can

368 lead to reduced uptake. It is therefore a positive sign that the model in no case

369 underestimated the experimental concentrations, and that often only a rather small

370 dissipation rate was sufficient (Table 3).

371 Two degradation kinetics were evaluated: first-order kinetics and Michaelis-

372 Menten. It is noteworthy to mention that the first-order kinetic has only one

373 parameter to adjust $(k)$ while Michaelis-Menten has two $\left(v_{\max }\right.$ and $\left.K_{M}\right)$. Moreover,

374 mathematical constraints did not allow considering the (known) dissipation from

375 soil. The first-order fit is therefore preferable in our case.

376 Measured root and leaf concentrations of BPA were very close to those predicted, 377 thus, no degradation rates were fitted (Table 3b). We did not find degradation

378 studies of BPA in plants for comparison. A large difference between predicted CAF

379 concentrations in leaves and measured values required to fit the $k_{\text {leaf }}$ to $1.50 \mathrm{~d}^{-1}$. 
380 Dettenmaier et al. (2009) derived the transpiration stream concentration factor

381 (TSCF) with a pressure chamber experiment of several organic compounds and 382 reported that polar neutral compounds such as CAF should be taken up rapidly by 383 roots and translocated to the leaves. On the other hand, Goldstein et al. (2014) and 384 Wu et al. (2014) reported that CAF was translocated to leaves less than CBZ due 385 to polar interactions. In the experiments of Hurtado et al. (2016), similar behavior 386 was observed, and the concentrations predicted for leaves were far above the 387 measured ones. Both phenomenon reduced translocation or rapid transformation 388 of CAF in leaves can lead to this discrepancy. In the literature, no degradation 389 rates have been reported for CAF in plants. Regarding CBZ, transformation 390 products (TPs) have been reported both for soil and plants, such as 10,11-epoxy 391 carbamazepine, 10,11-dihydroxycarbamazepine or 10,11-dihydro-10,11-dihydroxy392 carbamazepine (Goldstein et al., 2014; Malchi et al., 2014). Malchi et al. (2014) 393 reported that in soil, CBZ parent compound was dominant $(90 \%)$ and in leaves it 394 depended on the species (potato or carrot). Goldstein et al. (2014) reported similar 395 TPs and similar percentages in cucumbers and tomatoes. Metabolites formed in 396 soil can also be taken up by plants, which makes it difficult to differentiate where 397 exactly the degradation occurred.

398 Recently, Pietrini et al. (2015) detected 11 TPs of IBU in Lemna gibba L. plant 399 extracts when plants were exposed to $1 \mathrm{mg} \mathrm{L}^{-1}$ of IBU. In microalgae reactors, IBU 400 and CAF were rapidly biodegraded (Matamoros et al. 2016), while CBZ appeared 401 to be recalcitrant. In this case, the S-enantiomer of IBU was degraded faster. TCS 402 was metabolized in carrot and horseradish to conjugates, and the final amount of 
403 conjugates was five times higher than that of TCS (Macherius et al., 2012b). With

404 the fitted degradation rate in roots of $0.1 \mathrm{~d}^{-1}$, such a ratio would be reached after 18 405 days, it is thus reasonable. In horseradish, 33 metabolites of TCS were detected, 406 hereof 23 identified (Macherius et al., 2014)

\section{CONCLUSIONS}

409 Biodegradation of emerging contaminants in plants has been observed in many 410 cases but kinetics data are rare. Inverse modeling may provide a way to obtain this

411 missing information. Rates determined by inverse modeling are, despite the 412 inherent uncertainty, indicative of the dissipation rates. In the present study, 413 degradation kinetics was in the order $\mathrm{BPA}<\mathrm{CAF} \approx \mathrm{TCS}<\mathrm{CBZ}$ for roots, and BPA $414=\mathrm{TCS}<\mathrm{CBZ}<\mathrm{CAF}$ for leaves. There are indications that the high rate for CAF 415 could also compensate for less translocation than predicted.

416 In soil, decreasing first-order dissipation rates with increasing concentration were

417 observed. Co-metabolic degradation can explain this kinetics. The dissipation rates

418 were in the order TCS $\angle \mathrm{BPA} \approx \mathrm{CAF}<\mathrm{PROP} \approx \mathrm{IBU} \approx \mathrm{CBZ}$ for the lowest initial

419 concentration, and $\mathrm{TCS} \approx \mathrm{CBZ}<\mathrm{CAF} \approx \mathrm{BPA}<\mathrm{IBU} \approx \mathrm{PROP}$ at the highest applied 420 dose.

421 The shape of the BCF-curve (the ratio of concentration in plant to soil) and the $\mathrm{Y}$ 422 intercept gives information on the type of degradation kinetics. A negative $\mathrm{Y}$ 423 intercept can be obtained from (rapid) enzymatic degradation in plants. Finally, the 424 use of inverse modeling provides additional knowledge in the biodegradation of 
425 chemicals that can be taken up and further translocated in plants. This can be very 426 helpful to assess where biodegradation takes places and this method can be used 427 to study further metabolism in plant.

428 Dissipation kinetics found via inverse modeling is not a conclusive proof for 429 biodegradation and confirmation by experimental studies (for example, by 430 determination of metabolites or by studies with labeled compounds) is needed.

\section{AUTHOR INFORMATION}

433 Phone: +45 4525 1622, e-mail: stt@env.dtu.dk 


\section{Acknowledgments}

437 Authors thank to the Spanish Ministry of Economy and Competitiveness (MINECO)

438 for funding (CGL2011-24844 and AGL2014-59353-R). C.H. acknowledges a 439 predoctoral fellowship (BES-2012-055067) from MINECO and a short-stay grant

440 (EEBB-I-15-10049) to be able to travel to Denmark.

441 The authors would like to acknowledge the financial support provided by COST-

442 European Cooperation in Science and Technology, to the COST Action ES1403:

443 New and emerging challenges and opportunities in wastewater reuse (NEREUS).

\section{Disclaimer}

445 The content of this article is the authors' responsibility and neither COST nor any

446 person acting on its behalf is responsible for the use, which might be made of the 447 information contained in it. 
451 Calderón-Preciado, D., Jiménez-Cartagena, C., Matamoros, V., Bayona, J.M., (2011).

452 Screening of 47 organic microcontaminants in agricultural irrigation waters and 453 their soil loading. Water Res. 45, 221-231.

454 Carter, L.J., Harris, E., Williams, M., Ryan, J.J., Kookana, R.S., Boxall, A.B.A., 455 (2014). Fate and uptake of pharmaceuticals in soil-plant systems. J. Agric. Food. 456 Chem. 62, 816-825.

457 Clausen, L.P.W., Karlson, U.G., Trapp, S., (2015). Phytotoxicity of sodium fluoride 458 and uptake of fluoride in willow trees. Int. J. Phytorem. 17, 369-376.

459 Cousins, I.T., Staples, C.A., Kleĉka, G.M., Mackay, D., (2002). A multimedia 460 assessment of the environmental fate of bisphenol A. Hum. Ecol. Risk Assess. 8, $461 \quad 1107-1135$.

462 Dettenmaier, E.M., Doucette, W.J., Bugbee, B., (2009). Chemical hydrophobicity and 463 uptake by plant roots. Environ. Sci. Technol. 43, 324-329.

464 Directive 2008/105/EC of the European Parliament on environmental quality 465 standards in the field of water policy, amending and subsequently repealing 466 Council Directives 82/176/EEC, 83/513/EEC, 84/156/EEC, 84/491/EEC, 467 86/280/EEC and amending Directive 2000/60/EC of the European Parliament and 468 of the Council OJ L348/84

469 Dodgen, L.K., Li, J., Parker, D., Gan, J.J., (2013). Uptake and accumulation of four 470 PPCP/EDCs in two leafy vegetables. Environ. Pollut. 182, 150-156.

471 Dodgen, L.K., Li, J., Wu, X., Lu, Z., Gan, J.J., (2014). Transformation and removal 472 pathways of four common PPCP/EDCs in soil. Environ. Pollut. 193, 29-36. 
473 EMA European Medicines Agency, (2011). Questions and answers on 'Guideline on 474 the environmental risk assessment of medicinal products for human use'. 475 Document reference EMA/CHMP/SWP/44609/2010. Available at

476 http://www.ema.europa.eu.

477 Fantke, P., Wieland, P., Juraske, R., Shaddick, G., Itoiz, E.S., Friedrich, R., Jolliet, O., 478 (2012). Parameterization models for pesticide exposure via crop consumption. 479 Environ. Sci. Technol. 46, 12864-12872.

480 Fantke, P., Juraske, R., (2013). Variability of pesticide dissipation half-lives in plants. 481 Environ. Sci. Technol. 47, 3548-3562.

482 Fantke, P., Gillespie, B.W., Juraske, R., Jolliet, O., (2014). Estimating half-lives for 483 pesticide dissipation from plants. Environ. Sci. Technol. 48, 8588-8602.

484 Fent, G., Hein, W.J., Moendel, M.J., Kubiak R. (2003). Fate of 14C-bisphenol A in 485 soils, Chemosphere 51, 735-746.

486 Goldstein, M., Shenker, M., Chefetz, B., (2014). Insights into the uptake processes of 487 wastewater-borne pharmaceuticals by vegetables. Environ. Sci. Technol. 48, 55934885600.

489 Halling-Sørensen, B., Nors Nielsen, S., Lanzky, P.F., Ingerslev, F., Holten Lützhøft, 490 H.C., Jørgensen, S.E., (1998). Occurrence, fate and effects of pharmaceutical 491 substances in the environment- A review. Chemosphere 36, 357-393.

492 Hoagland, D.R., Arnon, D.I., (1950). The water-culture method for growing plants 493 without soil. Calif. Agric. Exp. Sta. Circ. 347, 1-32.

494 Hospido, A., Carballa, M., Moreira, M., Omil, F., Lema, J.M., Feijoo, G., (2010). 495 Environmental assessment of anaerobically digested sludge reuse in agriculture:

496 Potential impacts of emerging micropollutants. Water Res. 44, 3225-3233. 
497 Hurtado, C., Domínguez, C., Pérez-Babace, L., Cañameras, N., Comas, J., Bayona, 498 J.M., (2016). Estimate of uptake and translocation of emerging organic 499 contaminants from irrigation water concentration in lettuce grown under controlled 500 conditions. J. Hazard. Mater. 305, 139-148.

501 Jacobsen, R.E., Fantke, P., Trapp, S., (2015). Analysing half-lives for pesticide 502 dissipation in plants. SAR QSAR Environ. Res. 26, 325-342.

503 John Hendel, E.T., Lu, Z., Chapman, R., (2006). Biodegradation of caffeine in 504 agricultural soil. Can. J. Soil Sci. 86, 533-544.

505 Kästner, M., Nowak, K.M., Miltner, A., Trapp, S., Schäffer, A., (2014). Classification 506 and modelling of nonextractable residue (NER) formation of xenobiotics in soil - a 507 synthesis. Crit. Rev. Env. Sci. Tec. 44, 2107-2171.

508 Langdon, K.A., Warne, M.S.J., Smernik, R.J., Shareef, A., Kookana R.S. (2012). Field 509 dissipation of 4-nonylphenol, 4-t-octylphenol, triclosan and bisphenol A following 510 land application of biosolids, Chemosphere 86, 1050-1058.

511 Larsen, M., Trapp, S., Pirandello, A., (2004). Removal of cyanide by woody plants. 512 Chemosphere 54, 325-333.

513 Legind, C.N., Trapp, S., (2009). Modeling the exposure of children and adults via diet 514 to chemicals in the environment with crop-specific models. Environ. Pollut. 157, $515 \quad 778-785$.

516 Legind, C.N., Kennedy, C.M., Rein, A., Snyder, N., Trapp, S., (2011). Dynamic plant 517 uptake model applied for drip irrigation of an insecticide to pepper fruit plants. Pest. 518 Manag. Sci. 67, 521-527. 
519 Lin, A.Y.-C., Lin, C.-A., Tung, H.-H., Chary, N.S., (2010). Potential for biodegradation 520 and sorption of acetaminophen, caffeine, propranolol and acebutolol in lab-scale 521 aqueous environments. J. Hazard. Mater. 183, 242-250.

522 Löffler, D., Römbke, J., Meller, M., Ternes, T.A., (2005). Environmental fate of 523 pharmaceuticals in water/sediment systems. Environ. Sci. Technol. 39, 5209-5218. 524 Loos, R., Carvalho, R., António, D.C., Comero, S., Locoro, G., Tavazzi, S., 525 Paracchini, B., Ghiani, M., Lettieri, T., Blaha, L., Jarosova, B., Voorspoels, S., 526 Servaes, K., Haglund, P., Fick, J., Lindberg, R.H., Schwesig, D., Gawlik, B.M., 527 (2013). EU-wide monitoring survey on emerging polar organic contaminants in 528 wastewater treatment plant effluents. Water Res. 47, 6475-6487.

529 Luo, Y., Guo, W., Ngo, H.H., Nghiem, L.D., Hai, F.I., Zhang, J., Liang, S., Wang, X.C., 530 (2014). A review on the occurrence of micropollutants in the aquatic environment 531 and their fate and removal during wastewater treatment. Sci. Total Environ. 473$532474,619-641$.

533 Macherius, A., Eggen, T., Lorenz, W.G., Reemtsma, T., Winkler, U., Moeder, M., 534 (2012a). Uptake of galaxolide, tonalide, and triclosan by carrot, barley, and 535 meadow fescue plants. J. Agric. Food. Chem. 60, 7785-7791.

536 Macherius, A., Eggen, T., Lorenz, W., Moeder, M., Ondruschka, J., Reemtsma, T., 537 (2012b). Metabolization of the bacteriostatic agent triclosan in edible plants and its 538 consequences for plant uptake assessment. Environ. Sci. Technol. 46, 1079753910804.

540 Macherius, A., Seiwert, B., Schröder, P., Huber, C., Lorenz, W., Reemtsma, T., 541 (2014). Identification of plant metabolites of environmental contaminants by UPLC- 
542 QToF-MS: the in vitro metabolism of triclosan in horseradish. J. Agric. Food. 543 Chem. 62, 1001-1009.

544 Malchi, T., Maor, Y., Tadmor, G., Shenker, M., Chefetz, B., (2014). Irrigation of root 545 vegetables with treated wastewater: evaluating uptake of pharmaceuticals and the 546 associated human health risks. Environ. Sci. Technol. 48, 9325-9333.

547 Malchi, T., Maor, Y., Chefetz, B., (2015). Comments on "Human health risk 548 assessment of pharmaceuticals and personal care products in plant tissue due to 549 biosolids and manure amendments, and wastewater irrigation". Environ. Int. 82, $550 \quad 110-112$.

551 Miller, E.L., Nason, S.L., Karthikeyan, K.G., Pedersen, J.A., (2016). Root uptake of 552 pharmaceuticals and personal care product ingredients. Environ. Sci. Technol. 50, $553 \quad 525-541$.

554 Matsumura, Y., Akahira-Moriya, A., Sasaki-Mori, M. (2015). Bioremediation of 555 Bisphenol-A polluted soil by Sphingomonas bisphenolicum AO1 and the microbial 556 community existing in the soil, Biocontrol Sci 20, 35-42.

557 Monteiro, S.C., Boxall, A.B.A., (2009). Factors affecting the degradation of 558 pharmaceuticals in agricultural soils. Environ. Toxicol. Chem. 28, 2546-2554.

559 Pietrini, F., Di Baccio, D., Aceña, J., Pérez, S., Barceló, D., Zacchini, M., (2015).

560 Ibuprofen exposure in Lemna gibba L.: Evaluation of growth and phytotoxic

561 indicators, detection of ibuprofen and identification of its metabolites in plant and in 562 the medium. J. Hazard. Mater. 300, 189-193.

563 Polesel, F., Plósz, B.G., Trapp, S., (2015). From consumption to harvest: 564 Environmental fate prediction of excreted ionizable trace organic chemicals. Water 565 Res. 84, 85-98. 
566 Prosser, R.S., Trapp, S., Sibley, P.K., (2014). Modeling uptake of selected 567 pharmaceuticals and personal care products into food crops from biosolids568 amended soil. Environ. Sci. Technol. 48, 11397-11404.

569 Prosser, R.S., Sibley, P.K., (2015). Human health risk assessment of 570 pharmaceuticals and personal care products in plant tissue due to biosolids and 571 manure amendments, and wastewater irrigation. Environ. Int. 75, 223-233.

572 Rein, A., Legind, C.N., Trapp, S., (2011). New concepts for dynamic plant uptake 573 models. SAR QSAR Environ. Res. 22, 191-215.

574 Saiyood, S., Vangnai, A.S., Thiravetyan, P., Inthorn, D., (2010). Bisphenol A removal 575 by the Dracaena plant and the role of plant-associating bacteria. J. Hazard. Mater. $576 \quad 178,777-785$.

577 Trapp, S., Matthies, M., Scheunert, I., Topp, E.M., (1990). Modeling the 578 bioconcentration of organic chemicals in plants. Environ. Sci. Technol. 24, 12465791252.

580 Trapp, S., (2007). Fruit tree model for uptake of organic compounds from soil and air. 581 SAR QSAR Environ. Res. 18, 367-387.

582 Trapp, S., Feificova, D., Rasmussen, N.F., Bauer-Gottwein, P., (2008). Plant uptake 583 of $\mathrm{NaCl}$ in relation to enzyme kinetics and toxic effects. Environ. Exp. Bot. 64, 1-7. 584 Trapp, S., (2015). Calibration of a plant uptake model with plant- and site-specific 585 data for uptake of chlorinated organic compounds into radish. Environ. Sci. 586 Technol. 49, 395-402.

587 Walters, E., McClellan, K., Halden, R.U., (2010). Occurrence and loss over three 588 years of 72 pharmaceuticals and personal care products from biosolids-soil 589 mixtures in outdoor mesocosms. Water Res. 44, 6011-6020. 
590 Wu, C., Spongberg, A.L., Witter, J.D., Fang, M., Czajkowski, K.P., (2010). Uptake of 591 pharmaceutical and personal care products by soybean plants from soils applied 592 with biosolids and irrigated with contaminated water. Environ. Sci. Technol. 44, $593 \quad 6157-6161$.

594 Wu, X., Conkle, J.L., Ernst, F., Gan, J., (2014). Treated wastewater irrigation: uptake 595 of pharmaceutical and personal care products by common vegetables under field 596 conditions. Environ. Sci. Technol. 48, 11286-11293.

597 Wu, X., Dodgen, L.K., Conkle, J.L., Gan, J., (2015). Plant uptake of pharmaceutical 598 and personal care products from recycled water and biosolids: a review. Sci. Total 599 Environ. 536, 655-666.

$600 \mathrm{Xu}$, J., Wu, L., Chang, A.C., (2009). Degradation and adsorption of selected 601 pharmaceuticals and personal care products (PPCPs) in agricultural soils. 602 Chemosphere 77, 1299-1305.

603 Ying, G.-G., Kookana, R.S., Dillon, P., (2003). Sorption and degradation of selected 604 five endocrine disrupting chemicals in aquifer material. Water Res. 37, 3785-3791. 605 Yu, X., Trapp, S., Zhou, P., Wang, C., Zhou, X., (2004). Metabolism of cyanide by 606 Chinese vegetation. Chemosphere 56, 121-126. 
608 Figure Captions

609 Figure 1. Root and leaf bioconcentration factors (RCFs and LCFs) of 610 carbamazepine (CBZ) and ibuprofen (IBU). The solid and dashed lines represent 611 the linear regression of the root and leaf concentration on the applied initial and the 612 final soil concentration.

613

614 Figure 2. Simulated and measured concentrations in a) top left: CAF roots, b) top 615 right: CAF leaves, c) bottom left: BPA roots; d) bottom right: BPA leaves. Solid 616 points represent measured values; 00: no degradation in soil or plant; 1 st: 1 st order 617 degradation in soil, roots and leaves; MM: Michaelis-Menten degradation in roots 618 and leaves. 